\title{
The Research on the Green Productivity of High-carbon Industries in Resource-originated Region
}

\author{
YANG Jia-lei ${ }^{1}$, XUE Ji-liang ${ }^{2}$ \\ ${ }^{1}$ Northwest A\&F University, Shanxi,712100, China \\ ${ }^{2}$ Inner Mongolia University, Neimenggu,010021, China
}

\begin{abstract}
Keywords: Green productivity; High-carbon industries; Resource-originated region; Technological progress
\end{abstract}

\begin{abstract}
Based on the input and output data of eight high carbon industries in Hebei, Inner Mongolia, Shaanxi, Shanxi and Ningxia from the year of 2003 to 2011, this paper used Malmquist-Luenberger Productivity Index to estimate the green productivity and its decomposition. According to the empirical analysis of the economic development, structural factors, institutional factors and market factors, it can be found that constant income per capita and GDP growth rate significantly promote the growth of green TFP, technical efficiency and technical progress; the factor input structure and the industrial output value promote the growth of green TFP, technical efficiency and technical progress, but not all significantly above $10 \%$ and the significant level, at the same time the proportion of state-owned enterprises has significant negative effects on green TFP and technical progress; net exports promote the growth of green TFP, technical efficiency and technical progress, but the government intervention and fiscal decentralization is not conducive to growth of green TFP, technical efficiency and technical progress; energy prices significantly promote the growth of technical efficiency and technical progress and green TFP, and price changes has not obvious effect on them.
\end{abstract}

\section{Introduction}

The identification of resource-based regions is regions developed with the cost of ecological environment. The industries driven by massive resources mining and processing such as mineral and forest resources play a decisive role in development of regional economic for long [1]. The most representative ones in China are Hebei, Shanxi, Inner Mongolia and Ningxia province. They gathered high-carbon industries including steel, coal, cement and petrochemical, which forced enterprises to take the natural resources and environment into consideration sustainably and refrain from the limitation of natural wealth. Besides, these high-carbon industries contributed a lot to fog and haze in north China. Despite studying traditional production rates calculated by capital and labor this paper focused on the process of energy and environment in industrial development and the evolution of the rate under the environmental constraints. The result of paper aimed at supporting resource-based regions carbon reduction and environmental protection theoretically, and proposing for new industrialization in China.

\section{Literature Review}

There are massive researches on measuring production rate. According to Solow (1957), who utilized the growth accounting approach to measure the total factor productivity (TFP), TFP come from the technological advance deducting the contribution of inputting factors [2]. Since then, the way to estimate TFP had been widely adopted combining with advanced functions. However, based on Hailu's study in 2000, all those methods hardly consider the relationship between environment and sustainable development and they excessively concerned economic expansion instead of resource conservation and environmental protection [3]. Under the background of global sources shortage and aggravated pollution, it's vital for economists to add resources and environment into TFP estimation, which integrated energy, capital and labor with production function [4]; but what puzzled scholars was the exact market price of pollutions and how to calculated in production cost. 
To solve this problem, researchers such as Chen $\mathrm{K} \mathrm{H}$ et al decided to treat pollutions as a kind of input factors [5], and Chung et al (1997) [6] regarded the pollution as a kind of unexpected bad production. Both these two methods could solve this problem, while Chung`s reflected the ideology of better and faster well [7].

There also has been domestic studies on productivity calculation under the limitation of energy and environment. $\mathrm{Li}$ and $\mathrm{Xu}$ (2009) used the Non-parametric method to estimate the green TFP with pollution variables [8]; the result revealed huge differences between the green TFP indicator and the normal TFP indicator, while the green one showed little correlation with GDP. Chen (2010) recomputed TFP in the Chinese industry since 1978 based upon the Directional Distance Function, the result of which figured out the empirical TFP considering environmental constrains was lower than the normal one [9]. But policies on energy conservation and emissions reduction can be conducive to promote green industrial production ratio persistently. And $\mathrm{Hu}$ et al (2011) utilized the entropy approach to simulate the green comprehensive index of pollution [10]; in addition, they also estimated the green Malmquist index of each Chinese province by a nonparametric DEA-Malmquist model. Their study indicated that a) there was an apparent decline in TFP growth rate when considering environmental degradation; b) the green Malmquist indices did not reach absolute convergence as a whole but there appeared a typical club convergence in eastern China; c) technical progress was the key to regional economic development.

$\mathrm{Li}$ and Shen (2012) evaluated value and construction of each Chinese province`s TFP, which included three types of polluted emissions, through Global Malmquist-Luenberge (GML) productivity index approach [11]. The evaluation found out national industrial productivity in average increased in speed of $2 \%$ per year, and only in eastern China environmental technology efficiency was kept in a high level. The research conducted by Li and Tao (2012) turned out the intensity of environmental regulation currently fitting for these industries with serious contamination, and can accelerate innovation and efficiency in technology as well as promote green industrial TFP growth [12]. Whereas it showed a U-shape relationship between green TFP, innovation, efficiency in technology and industries polluted in mild or in middle concentration instead of a lined one. Ying (2012) employed SBM model to evaluate the value of green TFP in 27 manufacturing of China, which justified a clear lined relationship between intensity of environmental regulation and green TFP in manufacturing generally and found huge differences entre cleaner departments and pollution intensive departments in effects of environmental regulation intensity [13]. Furthermore, researches of $\mathrm{Wu}$ and Wen (2013) without efficiency of carbon emissions, productivity impacted industrial low-carbon development apparently, which climbed in high carbon intensity industries and fell in low carbon intensity industries [14]. They hold the view that technical progress worked more distinctly than technical efficiency in growth of green productivity and carbon economic development. According to Pan's [15] (2014) and Li's [16] (2014) studies on green agricultural productivity, it was necessary to combine resources and environment when developing.

Because of a serious unbalance in Chinese economic development, green productive technologies varied in different areas. Zhou (2014) decomposed and measured TFPs in industry of China by the way of global data envelopment analysis models and Malmquist-Luenberger index [17]. He found that technical progress drove TFP in industry increasing while technical efficiency hindered it; technical efficiency improved industrial carbon productivity more than technical progress did, and the facilitation effect by technical efficiency and progress in heavy industry was larger than that in light industry. Apart from working on productivity, these two factors can also accelerate TFP to rise. But capital deepening went against efficiency improvement, and decentralization as well as proportion of state-owned industries suppressed TFP`s improvement [18]. Wang et al (2015) figured the reason why green TFP increased in $0.73 \%$ per year from 2000 to 2012 in China was technical progress [19]. And his study also pointed the fact that productive technology in east was ahead of other areas. Ren et al (2015) learning by R\&D correlated with green TFP of industry nonlinearly and this relationship was characterized by mechanism transfer [20]; the effects by learning by $R \& D$ in green industrial TFP varied in different path and most provinces in China 
still depended on learning by R\&D path.

In conclusion, there is a good deal of literatures about green productivity in the view of methods and perspective. The deficiency in current studies arose in high-carbon industry located in resource-based regions. This paper aims to fill this gap. In the condition of productivity progress with environmental constraint, we decomposed green productivity in high-carbon industry in resource-based regions and explored the factors influenced productivity. So that we can offer proposals on new industrialization and environmental protection, then fill the gap of researching on carbon reduction in resource-based regional.

\section{Methodology}

The total factor productivity, as the economic performance of an important measure, could be measured mainly by: Solow residual method, Stochastic Frontier Analysis (SFA), algebraic index method and Data Envelopment Analysis (DEA). Among them, the Solow residual method and SFA need to set up production function form, and follow the specific assumptions related, and the estimated results is easy to be biased; and the algebraic index method only consider the market of "good" output, often ignore the "bad" the output which is non-market generated in the production process (Wang Bing et al. 2008) [21], which is contrary to the fact of environmental constraints increasingly tend in era of China's industrialization, which will distort the correct understanding of productivity (Wu Jun et al. 2010) [22]. In order to bring the environmental elements into the analysis framework of total factor productivity, which means considered "bad" energy inputs and pollution emission. Green total factor productivity of the Manchester kvist-Rouen Berg productivity index is used to measure the China manufacturing. Maqvist Runberg productivity index (ML index) do not need to set the optimal objectives and special producer production function, and the slack of input and output is solved, at the same time, it can avoid the radial and angular deviation and influence due to differences in the traditional DEA method (Yin Baoqing, 2012) [23]. The difference between the total factor energy efficiency is that the total factor energy efficiency is more concerned about the input and output of energy, while the green total factor productivity in this paper is more emphasis on environmental factors, and emphasizes the emission of pollutants. Estimation of total factor energy efficiency is often used in energy consumption data (Li Guozhang et al. 2010) [24], and in the green measure TFP not only consider joining the industrial energy consumption factors, pay more attention to the consideration of pollution emissions, such as carbon dioxide, waste gas emissions and solid waste generation.

In this paper, each industry is regarded as a production Decision Making Unit (DMU), and each production decision unit is assumed to have 3 inputs and outputs vectors, namely, input, the expected input and the expected output:

$$
X=\left(x_{1}, \ldots, x_{n}\right) \in R^{m \times n}, Y^{g}=\left(y_{1}^{g}, \ldots, x_{n}^{g}\right) \in R^{s_{1} \times n}, Y^{b}=\left(y_{1}^{b}, \ldots, x_{n}^{b}\right) \in R^{s_{2} \times n}, X>0, Y^{g}>0, Y^{b}>0
$$

In the case of constant returns to scale, the production feasibility set $P$ can be expressed as:

$$
P=\left\{\left(x, y^{g}, y^{b}\right) \mid x \geq X \lambda, y^{g} \geq Y^{g} \lambda, y^{b} \geq Y^{b} \lambda, \lambda \geq 0\right\}
$$

According to the SBM directional distance function of undesirable output Tone (2003) [25] it can be expressed as:

$$
\begin{aligned}
& \qquad \rho^{*}=\min \frac{1-\frac{1}{m} \sum_{i=1}^{m} \frac{S_{i}^{-}}{x_{i 0}}}{1+\frac{1}{S_{1}+S_{2}}\left(\sum_{r=1}^{s_{1}} \frac{S_{r}^{g}}{y_{r 0}^{g}}+\sum_{r=1}^{S_{2}} \frac{S_{r}^{b}}{y_{r 0}^{b}}\right)} \\
& \text { s.t. } x_{0}=X \lambda+s^{-} ; y_{0}^{g}=Y^{g} \lambda-s^{g} ; y_{0}^{b}=Y^{b} \lambda+s^{b} \\
& s^{-} \geq 0, s^{g} \geq 0, s^{b} \geq 0, \lambda \geq 0
\end{aligned}
$$

Among them, $S^{-}, s^{b}$ and $s^{g}$ are the amount of excessive investment, excessive emissions of pollution and the shortage of expected output. The objective function $\rho^{*}$ is strictly decreasing 
about $s^{-}, s^{b}$ and $s^{g}, 0 \leq \rho^{*} \leq 1$. If $\rho^{*}=1, s^{-*}=0, s^{g^{*}}=0, s^{b^{*}}=0$, the corresponding DMU was effective. According to the method of Chung (1997) [26], the green total factor productivity index (ML index) of stage $\mathrm{t}$ and $t+1$ was obtained:

$$
M L_{t}^{t+1}=\left\{\frac{\left[1+\vec{D}_{0 t}\left(x_{t}, y_{t}^{g}, y_{t}^{b} ; g_{t}\right)\right]}{\left[1+\vec{D}_{t}\left(x_{t+1}, y_{t+1}^{g}, y_{t+1}^{b} ; g_{t+1}\right)\right]} \times \frac{\left[1+\vec{D}_{t+1}\left(x_{t}, y_{t}^{g}, y_{t}^{b} ; g_{t}\right)\right]}{\left[1+\vec{D}_{t+1}\left(x_{t+1}, y_{t+1}^{g}, y_{t+1}^{b} ; g_{t+1}\right)\right]}\right\}^{\frac{1}{2}}
$$

The geometric average form of Eq. (3) can be widely applied to measure the presence of undesirable output green total factor productivity growth, but also can be further decomposed into technological progress index and production efficiency index, to explore the cause of productivity growth in the. Therefore, Eq. (3) can also be further written:

$$
\begin{aligned}
M L_{t}^{t+1}= & \frac{\left[1+\vec{D}_{0 t}\left(x_{t}, y_{t}^{g}, y_{t}^{b} ; g_{t}\right)\right]}{\left[1+\vec{D}_{t}\left(x_{t+1}, y_{t+1}^{g}, y_{t+1}^{b} ; g_{t+1}\right)\right]} \times\left[\frac{\left[1+\vec{D}_{t+1}\left(x_{t}, y_{t}^{g}, y_{t}^{b} ; g_{t}\right)\right]}{\left[1+\vec{D}_{0 t}\left(x_{t}, y_{t}^{g}, y_{t}^{b} ; g_{t}\right)\right]}\right. \\
& \left.\times \frac{\left[1+\vec{D}_{t}\left(x_{t+1}, y_{t+1}^{g}, y_{t+1}^{b} ; g_{t+1}\right)\right]}{\left.\vec{D}_{t+1}\left(x_{t+1}, y_{t+1}^{g}, y_{t+1}^{b} ; g_{t+1}\right)\right]}\right]^{\frac{1}{2}}=M E C_{t}^{t+1} \times M T C_{t}^{t+1}
\end{aligned}
$$

In Eq. (4), MLEC and MLTC represent production efficiency and technical progress, which can reflect the improvement of efficiency and the movement effect and change of production frontier (Li Jing, Shen Wei 2012) [27].

The resource type area is Hebei, Inner Mongolia, Shaanxi, Shanxi, and Ningxia; high carbon industry chose in this paper is the coal mining industry, ferrous metal mining industry, non-ferrous metal mining industry, oil processing and coking industry, pharmaceutical manufacturing, ferrous metal smelting and rolling industry non-ferrous metal smelting and rolling industry, electricity and heat production and supply industry. The selection of the 5 area and the 8 industry is mainly because of the high carbon industry is the main driving force of Hebei, Inner Mongolia, Shaanxi, Shanxi, Ningxia to economic growth, and also is a major source of pollution emissions. Furthermore, these areas are the largest contiguous area China resource type, or high carbon industry and industrial clusters of similar areas, and it is different from the South high carbon resources area; the study of the region of high carbon industry of green productivity is helpful to the enhancement of industrial competitiveness and industrial transformation.

Data using 2003-2011 years of industrial inter provincial panel data, the reason that the data is began in 2003 and ended in 2011 is that there are two nodes in the year of 2003 and 2011 the statistical variation of the diameter. The data are mainly from the provincial statistical yearbook, "the annual China Industrial Economic Statistical Yearbook", "Chinese Yearbook" and "China Environmental Statistics Yearbook", in which data processing of carbon dioxide from Chen (2010) method to calculate the shadow price of [28], at the same time some of the missing data are smoothed (Yang Jun, Shao Hanhua, 2009) [29].

The estimation of green productivity index are mainly aimed at the coal mining industry, ferrous metal mining industry, non-ferrous metal mining industry, oil processing and coking industry, pharmaceutical manufacturing, ferrous metal smelting and rolling industry, non-ferrous metal smelting and rolling industry, electricity. Input variables are industrial capital, labor and industrial energy consumption; the output is divided into desirable and undesirable outputs of two categories: the industrial added value represents the expected output, carbon dioxide emissions, and solid wastes is undesirable outputs.

In this paper, the MAXDEAP6.0 software is used by selecting the two-way model of investment priority to calculate the green total factor productivity of the high carbon industry in the resource-based regions. 


\section{Measurement of Green Total Factor Productivity of High Carbon Industry in Resource based Region}

The Manchester kvist Rouen - Berg (Malmquist-Luenberger Productivity Index productivity index, MLPI) is used to measure green productivity of high carbon industry in Hebei, Inner Mongolia, Shaanxi, Shanxi, Ningxia and other places. The results are shown in Table 1. From Table 1 can be found that green total factor productivity of coal mining industry in Hebei, nonferrous metal mining industry in Shaanxi, oil processing and coking coke industry and ferrous metal smelting and rolling industry in Ningxia of decreased, the high carbon industry in other areas of the green total factor productivity showed a growth trend; from the decomposition of green total factor productivity, petroleum processing and coking industry and electricity and heat production and supply industry in Hebei, petroleum processing and coking industry and ferrous metal smelting and rolling industry in Inner Mongolia, coal mining industry in Shanxi, non-ferrous metal mining industry, oil processing and coking industry, pharmaceutical manufacturing industry and the black metal smelting and rolling industry, Shanxi pharmaceutical manufacturing industry, petroleum processing, coking industry and ferrous metal smelting and rolling industry in Ningxia, the production efficiency above is inefficient, only the coal mining industry in Hebei has been in a state of decline, and other regions have high efficiency of carbon industry. Therefore, overall green productivity high carbon industry in Hebei, Inner Mongolia, Shaanxi, Shanxi, Ningxia and other places are efficient, and showed a growth trend. The average growth rate of $11.48 \%$; green productivity growth is mainly due to technological progress, the contribution is $61.72 \%$, followed by the productivity contribution, which is $38.28 \%$. The reason why is that technology investment is closely related. China provides advanced technology and equipment, advanced technology and technical transformation and development, improve the ability of re-innovation and independent innovation, to achieve a virtuous cycle of industry and technology options. These factors make technological progress become the main driving force of green productivity improvement. The level of economic development, structural factors, institutional factors and market factors are the main reasons for the improvement of green productivity.

From the average green productivity of high carbon industry in Hebei, Inner Mongolia, Shaanxi, Shanxi and Ningxia, green productivity in all regions of the present a growth trend, and be effective, which green productivity in Ningxia is the highest, followed by Shanxi; Shaanxi is the lowest; only Shaanxi's production efficiency is less than 1 , which shows the trend of invalid. And it is the leading cause of the lowest green productivity.

\section{Analysis and Comparison}

Main explanatory variables and descriptive statistics is shown as Table 2. From the point of economic development, the per capita income and the GDP growth rate have positive effects on green TFP, technical efficiency and technological progress, and the significant average level is above 10\%. This shows that with the development of economy and the growth of income, awareness of environmental protection, policies and responsibilities have been promoted. Therefore, the improvement of environmental technology efficiency and green technological progress will promote the growth of the green TFP in resource-based regions on high carbon industry.

From the view of structural factors, factor input structure and industrial output value have a positive effect on green TFP, technical efficiency and technical progress, but not all level of significance that above $10 \%$ mark. The capital deepening brought by the factor input structure promotes the growth of green TFP, high carbon industries in resource-based regions. Under the environmental regulation, it can promote the level of production equipment, improve efficiency and technological progress to promote the growth of green industrial TFP. Besides, the rapid industrialization of resource-based areas, which further brings about capital deepening, can also play a role in promoting the growth of industrial green TFP. However, the proportion of state-owned enterprises has a significant negative impact on green total factor productivity and technological 
progress, but the impact of technical efficiency is not significant. In fact, This can be explained from the governance structure and monopoly of state-owned enterprises. Due to the difficulty of solving the problem of principal agent in state owned enterprises, and it cannot overcome the disadvantage of monopoly, which leads to low efficiency of resource allocation of state owned (state-owned) enterprises and has no desire to promote cleaner production and energy efficiency. Accordingly, environmental constraints will soften and growth of industrial green TFP will be restricted. It is obvious that it reflects obviously in high carbon industry in Hebei, Inner Mongolia, Shanxi, Shanxi, Ningxia and other places.

Table 1 High carbon resource-based industries green decomposition of total factor productivity and changes in2003-2011

\begin{tabular}{|c|c|c|c|c|}
\hline Region & Industry & $\begin{array}{l}\text { Green total } \\
\text { factor } \\
\text { productivity }\end{array}$ & $\begin{array}{l}\text { Production } \\
\text { efficiency }\end{array}$ & $\begin{array}{l}\text { Technical } \\
\text { progress }\end{array}$ \\
\hline \multirow[t]{9}{*}{ Hebei } & Coal mining industry & 0.998 & 1.000 & 0.998 \\
\hline & Ferrous metal mining industry & 1.239 & 1.227 & 1.009 \\
\hline & Nonferrous metal mining industry & 1.117 & 1.052 & 1.061 \\
\hline & Petroleum processing and coking industry & 1.119 & 0.960 & 1.166 \\
\hline & Pharmaceutical manufacturing & 1.063 & 1.025 & 1.037 \\
\hline & Ferrous metal smelting and rolling industry & 1.098 & 1.085 & 1.012 \\
\hline & Non-ferrous metal smelting and rolling industry & 1.126 & 1.102 & 1.021 \\
\hline & Electric power production and supply & 1.061 & 0.964 & 1.101 \\
\hline & average value & 1.103 & 1.052 & 1.051 \\
\hline Inner & Coal mining industry & 1.127 & 1.096 & 1.028 \\
\hline \multirow[t]{8}{*}{ Mongolia } & Ferrous metal mining industry & 1.079 & 1.060 & 1.017 \\
\hline & Nonferrous metal mining industry & 1.149 & 1.118 & 1.028 \\
\hline & Petroleum processing and coking industry & 1.031 & 0.952 & 1.083 \\
\hline & Pharmaceutical manufacturing & 1.124 & 1.122 & 1.002 \\
\hline & Ferrous metal smelting and rolling industry & 1.052 & 0.972 & 1.083 \\
\hline & Non-ferrous metal smelting and rolling industry & 1.015 & 1.008 & 1.008 \\
\hline & Electric power production and supply & 1.176 & 1.076 & 1.094 \\
\hline & average value & 1.094 & 1.051 & 1.043 \\
\hline \multirow[t]{9}{*}{ Shanxi } & Coal mining industry & 1.014 & 0.993 & 1.022 \\
\hline & Ferrous metal mining industry & 1.124 & 1.049 & 1.072 \\
\hline & Nonferrous metal mining industry & 0.959 & 0.933 & 1.028 \\
\hline & Petroleum processing and coking industry & 1.009 & 0.954 & 1.058 \\
\hline & Pharmaceutical manufacturing & 1.003 & 0.974 & 1.030 \\
\hline & Ferrous metal smelting and rolling industry & 1.075 & 0.985 & 1.091 \\
\hline & Non-ferrous metal smelting and rolling industry & 1.212 & 1.083 & 1.119 \\
\hline & Electric power production and supply & 1.175 & 1.023 & 1.148 \\
\hline & average value & 1.071 & 0.999 & 1.071 \\
\hline \multirow[t]{9}{*}{ Shanxi } & Coal mining industry & 1.224 & 1.214 & 1.008 \\
\hline & Ferrous metal mining industry & 1.268 & 1.000 & 1.268 \\
\hline & Nonferrous metal mining industry & 1.169 & 1.081 & 1.081 \\
\hline & Petroleum processing and coking industry & 1.133 & 1.075 & 1.054 \\
\hline & Pharmaceutical manufacturing & 1.042 & 0.999 & 1.044 \\
\hline & Ferrous metal smelting and rolling industry & 1.225 & 1.079 & 1.135 \\
\hline & Non-ferrous metal smelting and rolling industry & 1.113 & 1.100 & 1.013 \\
\hline & Electric power production and supply & 1.121 & 1.000 & 1.121 \\
\hline & average value & 1.162 & 1.069 & 1.091 \\
\hline \multirow[t]{8}{*}{ Ningxia } & Coal mining industry & 1.262 & 1.105 & 1.142 \\
\hline & Ferrous metal mining industry & 1.235 & 1.136 & 1.087 \\
\hline & Nonferrous metal mining industry & 1.139 & 1.062 & 1.072 \\
\hline & Petroleum processing and coking industry & 0.975 & 0.892 & 1.092 \\
\hline & Pharmaceutical manufacturing & 1.147 & 1.052 & 1.090 \\
\hline & Ferrous metal smelting and rolling industry & 0.998 & 0.915 & 1.090 \\
\hline & Non-ferrous metal smelting and rolling industry & 1.232 & 1.142 & 1.078 \\
\hline & Electric power production and supply & 1.162 & 1.017 & 1.142 \\
\hline
\end{tabular}




\begin{tabular}{|c|c|c|c|c|}
\hline \multicolumn{2}{|c|}{ average value } & 1.144 & 1.0401 & 1.099 \\
\hline Whole & Average & 1.115 & 1.042 & 1.071 \\
\hline
\end{tabular}

From the view of institutional factors, net export proportion has a positive effect on green TFP, technical efficiency and technical progress, but not all level of significance that above $10 \%$ mark. Hebei, Inner Mongolia, Shaanxi, Shanxi, Ningxia and other places of high carbon industry are in the forefront of the industry chain, whose products are mainly supplied to domestic downstream. In addition, the import and export value of these 5 regions are mostly negative, leading to be influenced by foreign raw materials in Hebei, Inner Mongolia, Shaanxi, Shanxi, Ningxia and other places of high carbon industry. Therefore, reducing imports of foreign raw materials will contribute to the high carbon industry to enjoy the price advantage, become convenient to improve the efficiency of environmental technology and green technology, and be more likely to promote industrial green TFP growth. Government intervention and fiscal decentralization are not conducive to the growth of green TFP, technical efficiency and technological progress. Government intervention has a significant negative effect on environmental technology efficiency and green TFP, while it is in favor of industrial green TFP growth. Under the guidance of GDP oriented tournament official promotion system, the distorted fiscal expenditure structure of local protection zone Ali has a negative impact on the regional economic growth, and it cannot effectively stimulate local government energy conservation and emission reduction. Similarly, fiscal decentralization will not play a role in promoting the improvement of environmental performance, on the contrary will hinder the growth of green Tapetis is related to the existing fiscal decentralization system, decentralization system and GDP oriented performance evaluation mechanism are difficult to curb environmental pollution and destruction, and thus damage the green TFP growth of high carbon industry in resource-based areas.

From the view of market factors, energy price has a positive effect on green TFP, technical efficiency and technical progress, and it marks. High carbon industry in resource-based areas has a higher sensitivity to energy price changes, the change of price bringing the forced mechanism will promote the high carbon industry to adopt more advanced and effective emission reduction technology, and improve the efficiency of environmental technology and green technology, then significantly promote the growth of green TFP. However, the impact of price changes on efficiency, technological progress and green TFP growth is not obvious.

Table 2 The definition of main explanatory variables and descriptive statistics

\begin{tabular}{|c|c|c|c|c|c|c|}
\hline & Variable & Definition & Minimum & Maximum & Average & $\begin{array}{l}\text { Standard } \\
\text { deviation }\end{array}$ \\
\hline \multirow{2}{*}{$\begin{array}{l}\text { Economic } \\
\text { development } \\
\text { level }\end{array}$} & $\begin{array}{l}\text { Constant price per } \\
\text { capita income }\end{array}$ & $\begin{array}{l}\text { Per capita income at } \\
\text { constant prices in } \\
2003\end{array}$ & 7028.00 & 57974.00 & 20619.82 & 11002.63 \\
\hline & GDP growth rate & $\begin{array}{l}\text { Real GDP growth rate } \\
\text { excluding } \\
\text { factors }\end{array}$ & 105.40 & 123.80 & 113.83 & 3.17 \\
\hline \multirow{3}{*}{$\begin{array}{l}\text { Structural } \\
\text { factors }\end{array}$} & $\begin{array}{l}\text { Factor input } \\
\text { structure }\end{array}$ & $\begin{array}{l}\text { Depreciation of fixed } \\
\text { assets }\end{array}$ & 0.21 & 0.46 & 0.33 & 0.07 \\
\hline & $\begin{array}{l}\text { Proportion of } \\
\text { state-owned } \\
\text { enterprises }\end{array}$ & $\begin{array}{l}\text { The output value of } \\
\text { state-owned and state } \\
\text { holding enterprises }\end{array}$ & 0.41 & 0.52 & 0.45 & 0.05 \\
\hline & $\begin{array}{l}\text { Industrial output } \\
\text { ratio }\end{array}$ & $\begin{array}{l}\text { Industrial output value } \\
\text { /GDP }\end{array}$ & 0.32 & 0.53 & 0.44 & 0.05 \\
\hline \multirow{3}{*}{$\begin{array}{l}\text { Institutional } \\
\text { factors }\end{array}$} & $\begin{array}{l}\text { Import and export } \\
\text { ratio }\end{array}$ & $\begin{array}{l}\text { Net exports of goods } \\
\text { and services /GDP }\end{array}$ & -0.48 & 0.15 & -0.12 & 0.17 \\
\hline & $\begin{array}{l}\text { government } \\
\text { intervention }\end{array}$ & $\begin{array}{l}\text { Local finance } \\
\text { accounted for the } \\
\text { proportion of total } \\
\text { revenue }\end{array}$ & 0.45 & 0.51 & 0.47 & 0.02 \\
\hline & $\begin{array}{l}\text { Fiscal } \\
\text { Decentralization }\end{array}$ & $\begin{array}{l}\text { Fiscal expenditure } \\
\text { ratio }\end{array}$ & 0.26 & 0.64 & 0.44 & 0.09 \\
\hline
\end{tabular}




\begin{tabular}{lclllll}
\hline \multirow{2}{*}{$\begin{array}{c}\text { Market } \\
\text { factors }\end{array}$} & Energy price index & $\begin{array}{l}\text { In 2003 the fuel price } \\
\text { index base period }\end{array}$ & 89.20 & 120.60 & 109.47 & 9.02 \\
\cline { 2 - 6 } & CPI & Consumer Price Index & 98.82 & 107.90 & 103.05 & 2.15 \\
\hline
\end{tabular}

\section{Conclusions and Recommendations}

This study is based on the 8 high carbon industry input-output data, including the coal mining industry, ferrous metal mining industry, non-ferrous metal mining industry, oil processing and coking industry, pharmaceutical manufacturing, ferrous metal smelting and rolling industry, non-ferrous metal smelting and rolling industry, electric power production and supply industry in Hebei, Inner Mongolia, Shaanxi, Shanxi, Ningxia and other 5 resource-based regions. By Manquis Berg - Rouen productivity index estimation of green productivity and its decomposition. The level of economic development, structural factors, institutional factors and market factors empirical analysis of high carbon industry influence resource type area green productivity and its specific factors decomposition the results showed. (1) The constant price of per capita income and growth rate of GDP significantly promote the green TFP, technical efficiency and technical progress of growth. (2) Factor input structure and industrial output value accounted for the ratio of green TFP, technical efficiency and technical progress is positive, but not more than $10 \%$,while, green total factor productivity, technological progress the proportion of state-owned enterprises has a significant negative impact, but have no significant effect on the technical efficiency. (3) Net exports significant influence of net exports accounted for ratio of green TFP, technical efficiency and technical progress is positive, but the government intervention and fiscal decentralization is disadvantageous to the green TFP, technical efficiency and technical progress and growth. (4) Energy prices significantly promote the technical efficiency, technology with the progress of green TFP growth, while the price change effect on operation efficiency, technological progress and green TFP growth is not obvious. Therefore, in order to promote the technological efficiency, technological progress and the synchronous growth of green TFP in the high carbon industry in resource based areas, it needs to be done:

(1) To resolve the negative effects of decentralization on economic growth and low carbon transformation of high carbon industry. Although the decentralization of the "championship" system can effectively stimulate the local economic development, but the transition stressed that economic development will relax the governance and protection of the ecological environment. In order to solve this problem, it is best to moderate reform between the moderate decentralization and local government performance evaluation mechanism, implement the function of energy saving and emission reduction performance in the performance evaluation, strengthen environmental preferences and environmental performance of local fiscal expenditure, as far as possible to avoid capital deepening losses brought by the degree of environmental performance [30].

(2) The energy price index with a certain regional influence should be established in resource based areas, through the establishment of certain regional influence energy price index to promote the industry stable and healthy development and promote the coordinated development of real market and virtual market, avoid the negative impact of price fluctuation on green productivity, promote the high carbon industry low carbon transition. In order to provide the help for the active coal trade, through the establishment of the energy price index, to promote the coal information and the financial innovation of the coal, and then achieve the goal of the transformation and development of the resource-based city and the overall situation of the national economy [31].

(3) Increase the intensity of technology introduction and independent innovation. To realize the harmonious relationship between environmental protection and economic development through the new industrialization of technological progress and technological choice. The companies can learn from foreign advanced technology, through innovation and development and constantly improve the technical level, to improve the allocation efficiency and resources utilization efficiency; In addition, take various measures to increase the development of green technology investment, and encourage enterprises to carry out green technology innovation and management innovation in the production process to achieve energy-saving emission reduction, to achieve to improve the high carbon 
industry green to improve productivity [32].

\section{References}

[1] Fei Cai, Hong Jin. The Judgment of the Resource-based Regions in China with the Theory on Location Entropy [J]. Technoeconomics \& Management Research, 2010(2): 142-144.

[2] Solow R K. Technical change and the aggregate production function[J]. Review of Economic Review, 1957, 39(3):312-320.

[3] Hailu A, Veeman T S. Environmentally sensitive productivity analysis of the Canadian pulp and paper industry [J]. Journal of Environmental and Management, 2000,40(3):251-274

[4] Ayres R U, Ayres L W, Warr B. Exergy, power and work in the US economy: 1900-1998[J]. Energy, 2003, 28(3):219-273

[5] Chen K H, Huang Y J, Yang C H. Analysis of regional productivity growth in China [J]. China Economic Review, 2009, 20(4):777-792

[6] Chung Y H, Fare R, Grosskopf S. Productivity and undesirable outputs: a directional distance function approach [J]. Journal of Environmental Management, 1997, 51(3):229-240

[7] Kumar S. Environmentally sensitive productivity growth: a global analysis using malmquist -luenberger index [J]. Ecological Economics, 2006, 56(2):280-293

[8] Jun Li, Jintao Xu. Analysis of Inter-provincial Green Total Factor Productivity Application of a Non-parametric Method [J]. Journal of Beijing Forestry University (Social Sciences), 2009(4): 139-146.

[9] Shiyi Chen. Green Industrial Revolution in China: A Perspective from the Change of Environmental Total Factor Productivity [J]. Economic Research Journal, 2010(11): 21-34+58.

[10] Xiaozhen $\mathrm{Hu}$, Long Yang. Analysis of Growth Differences and Convergence of Regional Green TFP in China [J]. Journal of Finance and Economics, 2011(4): 123-134

[11] Jing Li, Wei Shen. Environmental Regulation and Industrial Green Total Factor Productivity in China: An Empirical Re- Examination on Porter Hypothesis [J]. Joumal of Shanxi Finance and Economics University, 2012(2):56-65.

[12] Ling Li, Feng Tao. Selection of Optimal Environmental Regulation Intensity for Chinese Manufacturing Industry: Based on the Green TFP Perspective [J]. China Industrial Economics, 2012(5): 70-82.

[13] Baoqing Li. Environmental Regulation and China’s Green Total Factor Productivities: Based on the Perspective of Vertical Specialization [J]. China Pollution, Resources and Environment, 2012(12): 60-66.

[14] Yingzi Wu, Yuechun Wen. Research on the Green Productivity and Its Impact on Industrial Low-carbon Development [J]. Journal of Management Science, 2013(1): 112-120.

[15] Dan Pan. Agricultural Green Technical Efficiency Evaluation and Its Determinants in China [J]. Statistics \& Information Forum, 2014(8):27-33.

[16] Gucheng Li. The Green Productivity Reformation in China: 1978-2008 [J]. China Economics Quarterly, 2014(2): 537-558.

[17] Wuqi Zhou. The Effect of Efficiency Improvement and Technological Progress on Green Productivity Growth: An Empirical Analysis for 36 Sub-industrial Sectors in China [J]. 2014(4): 63-69. 
[18] Wuqi Zhou, Ge Wu. Industrial Green TFP Growth under Low-Carbon Constraint and Its Influencing Factors Analysis [J]. Forum on Science and Technology in China, 2014(8): 67-73.

[19] Keliang Wang, Xiangrui Meng, Li Yang, Yunhe Chen. Heterogeneous Production Technology and Regional Green Total-factor Productivity Growth: An Analysis based on Meta-frontier and China's Provincial Panel Data of 2000-2012 [J]. Journal of Beijing Institute of Technology (Social Sciences Edition), 2015(1):23-31.

[20] Yao Ren, Chongwei Niu, Tongjin Zhang. Impacting on Industrial Green Total Factor Productivity of Learning by R\&D: Based on Revised PSTR Model [J]. On Economic Problems, 2015(3): 71-75.

[21] Bing Wang, Yanrui Wu, Pengfei Yan. Environmental Regulation and Total Factor Productivity Growth: An Empirical Study of the APEC Economies. Economic Research, 2008, 5, 19-32.

[22] Jun Wu, Fengyuan Da, Jianhua Zhang. Environmental Regulation and Regional TFP Growth of China[J]. Statistical Research, 2010, 27(1), 84-89.

[23] Yin Baoqing. The Impact of Environmental Regulation on Enterprise's Efficiency of Technology Innovation in China-An Empirical Test Based on the Three Major Economic Regions of China[J]. Journal of Poyang Lake, 86-95.

[24] Guozhang Li, Zongjie Huo. Total Factor Energy Efficiency of China and its Convergence[J]. CHINA POPULATION,RESOURCES AND ENVIRONMENT, 2010, 20(1), 11-16.

[25] Tone K. Dealing with Undesirable Output in DEA: A Slacks-based Measure (SBM) Approach[J]. GRIPS Research Report Series No.I-2003-005, 2003

[26] Chung Y H, Fare R, Grosskopf S. Productivity and Undesirable Output: A Directional Distance Function Approach [J]. Journal of Environmental Management, 1997, 51(3): 229-240

[27] Jing Li, Wei Shen. Environmental Regulation and Industrial Green Total Factor Productivity in China[J]. Journal of Shanxi finance and Economics University, 2012, 34(2), 56-65.

[28] Shiyi Chen. Shadow prices of industrial carbon dioxide: parametric and nonparametric methods[J]. World Economy, 2010, 8,93-111.

[29] Jun Yang, Hanhua Shao. Empirical Study on China's Industrial Growth under the Binding of Environment[J]. Quantitative Economic and Technical Research. 2009(9): 64-78.

[30] Xu GuangYue, Song Deyong, An Empirical Study on China's carbon emissions environmental Kuznets curve: Based on Provincial Panel Data [J]. China industrial economy, 2010 (5): 37-47

[31] Song Xuguang, Xi Wei. Chinese energy structure changes in productivity growth — the analysis based on Shift-Share method [J]. Research on Financial and Economic Issues, 2010 (10): 8-13

[32] Li Ling, Tao Feng. Study on total factor productivity and influencing factors of green industry in China [D]. doctoral dissertation of Jinan University, 2012 